\title{
Negotiating Chinese Identity in the Internet Age
}

\author{
Ritendra Tamang, PhD \\ Anthropology Program \\ University of Northern British Columbia \\ 3333 University Way \\ Prince George, BC V2N 4 Z9 \\ Canada \\ E-mail: tamang@unbc.ca
}

\begin{abstract}
The advent of the internet has led to the globalization of cultural images of Chinese identity. Online Chinese immigrants' associations, in conjunction with Chinese-language electronic media, offer various and often competing images of Chinese ethnic and cultural identities. The multiple representations of Chinese identity in the various media formats provide options for individuals to negotiate their identity and belonging in different contexts. This paper examines the roles that the internet plays in influencing ethnic identity among Chinese immigrants in the province of British Columbia, Canada. I argue that the array of images offered by online Chinese-language media websites and virtual communities create more options for individual Chinese immigrants to negotiate and redefine their ethnic and cultural identities in relation to other Chinese and non-Chinese immigrant groups.
\end{abstract}

Keywords: Chinese, Ethnicity, Globalization, Hybridity, Identity, Immigrants, Internet

\section{Introduction}

Public debates on immigration in Canada increasingly focus on the influences that immigrants have on shaping Canadian ethnic and cultural diversity (P. S. Li, 2003, p. 54). Since the early 1960s, expansion of the global economy, in conjunction with changes to Canada's immigration and citizenship laws and policies, has encouraged various waves of Chinese people - especially those engaged in transnational trade and business - to immigrate to Canada from various parts of the world. Frequent movement between societies allows individuals not only to redefine their ethnic and cultural identities but also to have a sense of belonging to various locations simultaneously. In addition, the rise of electronic mass media and the establishment of online communities among Chinese immigrants around the world has given rise to new cultural images of Chinese ethnic and cultural identities among Chinese immigrants in Canada.

Within Canada, racial, ethnic, and cultural differences are important markers of distinction between immigrant groups. At the same time, these differences serve to confirm individual membership within a community. For many recently arrived Chinese immigrants in Canada, the internet is useful for accessing information about settlement, public services, and employment opportunities. Chinese immigrants also use the internet to learn and preserve their cultural traditions. In this paper, I will examine the role that the internet plays in shaping individual identity among Chinese immigrant groups in the Canadian province of British Columbia. I will argue that the globalization of Chinese images has created new and alternative spaces for individual Chinese immigrants in British Columbia to redefine their ethnic identity and cultural identity as well as to differentiate themselves from others perceived as non-Chinese in the province, across the country, and across national borders.

\section{Internet and the Construction of Ethnicity}

In recent years, the internet has received significant attention from scholars across disciplines. Researchers increasingly focus on the politics that exist in the rhetoric and representation of Chinese ethnic identity on the internet. Similar to other material cultural artifacts, the internet is socially constructed and thereby has significant socioeconomic and political implications. A popular subject of debate among scholars and researchers is whether the internet is being used to create a homogenous or a heterogenous world. While the internet has been seen as means of constructing homogeneity and social control by elite groups, it also provides possibilities for individuals and groups to challenge dominant rhetoric and representation (Nye, 2006, p. 608; Wanning, 2005, pp. 66-67). As such, the internet must be seen as a system of tools, materials, structures... and techniques under human control. Societies continually add and subtract items from their repertoire, and in using them they often come into conflict, as they construct diverse [individual and group] life-worlds. (Nye, 2006, p. 614) 
Local populations in various parts of the world have sought to integrate certain cultural products and practices offered by the worldwide web into their own practices and beliefs, thereby creating hybrid cultures (Nye, 2006, p. 607). For this reason, the internet is an effective tool not only for preserving immigrant cultures but also for contesting and reinventing cultural identities and beliefs (p. 613).

The internet has increased flows of Chinese cultural images across national borders. Consequently, the majority of Chinese immigrants in Canada and other host societies around the world can access various online Chinese-language media to fulfill their particular needs (Wanning, 2005, p. 66). However, differences in educational and socioeconomic backgrounds contribute to unequal internet access among Chinese groups in Canada (Nye, 2006, p. 606). In this way, the internet has contributed to the emergence of a new global economic hierarchy among immigrant groups. Sun Wanning (2005, p. 66) and Brenda Chan (2006, p. 2) suggest that the rise of Chinese-language electronic media products (e.g., online magazines and newsgroups) in democratic countries such as Canada further contribute to the process of redefining Chinese identity among Chinese migrant groups within a transnational context. Together, the various images offered by the internet challenge and reinforce individual Chinese immigrants' perceptions and understanding of what it means to be Chinese.

Currently, three dominant versions of Chinese identity exist on the internet. The first is linked to the identification with and loyalty to the Chinese Communist Party and its political ideology of socialism. Being Chinese is also linked to the idea of belonging to the Han ethnic identity, especially for many Chinese immigrants from mainland China, Taiwan, Hong Kong, and Macau. Finally, Chinese identity is closely tied to Confucianism, which many Chinese groups around the world perceive as an essential feature of Chinese culture (Chan, 2006, p. 7). Internet users therefore have the option of accessing a range of interpretations and meanings of Chinese and Chinese culture. In addition, virtual (online) communities comprising mostly educated and professional Chinese immigrants provide various representations of Chinese identity and provide the individual with opportunities to negotiate her or his identity and belonging (Wanning, 2005, p. 67).

In Canada, Chinese immigrants arriving from various parts of the world possess their own cultures, histories, and experiences of what it means to be Chinese (Wickberg, 2007, p. 178). Local Canadian versions of Chinese identity and culture often compete with ideas that recent Chinese immigrants bring from their previous homelands (Chan, 2006, p. $3)$.

The term Chinese thus disguises multiple layers of local and national identities and social status. This article will use this term to refer to ethnicity, nationality, and citizenship.

\section{Immigration and Ethnicity in Canada}

The Canadian government divides immigrants into three categories-family class, economic class, and refugee class - for its selection and admission process (P. S. Li, 2003, p. 39). Within the dominant media and public discourse, the term immigrants is ambiguous and is often used to refer to those who are racially, ethnically, or culturally different from those of British and French backgrounds (p. 44). Immigration has played and continues to play significant roles in the construction of Canadian identities. Historically, Canadian immigration policy favored immigrants from Europe (mainly Britain) and the United States (p. 18). However, other European and non-European immigrant groups also chose to migrate to Canada in search of a better life and economic opportunities (p. 160).

In Canada, as in the United States, Chinese immigration has a long history. The gold rushes in the Fraser Valley in 1859 and western railroad construction from 1881 to 1885 stimulated demand for Chinese labor in British Columbia (P. Li, 2008, p. 160). Early Canadian nationalist rhetoric and dominant culture sought to portray Canada as a nation dominated by a white working-class population (P. Li, 2008, p. 128). Non-European immigrants such as the Chinese were seen as beneficial to the country's socioeconomic development and therefore permitted to enter, but in limited numbers (Wickberg, 2007, p. 186).

The idea of migration as an economic investment was widely shared by the majority of Chinese immigrants. Along with the Chinese immigrant working class, Chinese merchants also came to the province (Chu, 2006, p. 393).

Early Chinese immigrants contributed significantly to the socioeconomic development of British Columbia, especially in railroad construction (P. Li, 2008, p. 127). The construction of the Canadian Pacific Railway during the late 1800s attracted many Chinese from mainland China (Wickberg, 2007, p. 186). However, their contributions were undermined by Canada's restrictive immigration and citizenship policies. Upon the completion of the Canadian Pacific Railway in British Columbia during the 1880s, the Canadian government introduced the Chinese Immigration Act, which required individual Chinese immigrants to pay a head tax of $\$ 50$ upon entering the country (Chu, 2006, p. 397). The Act also specified that vessels arriving in Canada "could not carry more than one Chinese person for every fifty tons of tonnage" (p. 397). Those who paid the head tax were issued a certificate of entry by the government. However, Chinese immigrants were required to turn in their certificates if they left the country, even for a short period of time, or risk being barred from re-entering. Those who chose to leave could stay outside the country for up to one year; otherwise, 
they were required to pay the head tax again. Unlike poor Chinese workers, Chinese clergymen, Chinese merchants and non-Chinese migrants did not have to pay a new head tax upon re-entry. Additionally, whereas wealthy Chinese merchants' wives and children were exempt from paying the head tax upon entering the country, poor immigrant workers were forced to pay a heavy price to have their families join them in Canada (p. 398). The head tax thus contributed to a gender imbalance among the early Chinese immigrant population in Vancouver and elsewhere in Canada. Differential treatments of Chinese immigrant groups meant that the chances of immigration for Chinese women and their children were contingent upon their partners' occupations and financial status.

Realizing that $\$ 50$ was not enough to discourage Chinese immigrants from entering the country, the Canadian federal government increased the head tax to $\$ 100$ in 1900 and $\$ 500$ three years later (Chu, 2006, p. 399; Goutor, 2007, p. 561; P. Li, 2008, p. 127-128). The increased head tax successfully discouraged many Chinese immigrants from immigrating to Vancouver (P. Li, 2008, p. 129). At the end of WWI, the economic crisis in British Columbia and elsewhere led to further restrictions on the number of Chinese immigrants entering the province (Chu, 2006, p. 400). By 1923, the Canadian government introduced the Chinese Immigration Act, which banned Chinese immigration altogether. Chinese immigrants who were already in Canada were denied certain rights and privileges that many white settlers took for granted, such as voting, participating in all occupations, and traveling freely (P. Li, 2008, p. 128). Chinese immigrants were often labeled by Canada dominant racial discourses as "dirty, lazy, and alien"; these racial stereotypes further reinforced the idea of Chinese people as an "inferior race" (Chu, 2006, p. 396).

Throughout the $1890 \mathrm{~s}$, a series of anti-Asian campaigns were organized by various union leaders against Chinese and other Asian immigrant workers in British Columbia (Goutor, 2007, p. 561). By accepting low wages, Chinese workers, according to the unions, were undermining "the standards of living of Canadian workers, or driving them out of industries altogether" (p. 554). In addition to the economic reason, race was also used by white labor leaders in British Columbia to reinforce their anti-Asian rhetoric campaign. Goutor suggests that the racist attitudes displayed by white labor leaders stemmed mainly from these individuals' "fear ... desires, and personal characteristics they hated most. The results were jumbles of contradictory stereotypes that were attached to a racialized group" (p. 569). The Chinese were often portrayed by European dominant media as "sexual predators who sought to take advantage of white women" (p. 556). The racial sentiments displayed by white male labor leaders reflected the politics of racial purity in Vancouver and elsewhere in Canada, where the mixing of different racial or ethnic groups was discouraged. Compared to their male counterparts, Chinese women's sexuality was perceived as less threatening to the dominant white population in British Columbia (Chu, 2006, p. 394). British immigrant workers, on the other hand, were represented as "honest" and "hardworking" workers (Goutor, 2007, p. 557).

Canadian restrictive immigration policies had important consequences for individuals and communities of Chinese immigrants in British Columbia and elsewhere in Canada. The head tax, in conjunction with the anti-Asian campaigns, prevented the majority of Chinese immigrants in British Columbia from bringing their families over and discouraged many Chinese women from immigrating to the province. Many women with spouses in British Columbia remained in China to care for their children and extended families. The practice of remittances provided economic support for many of those who stayed behind (Chu 2006, p. 394).

Migration was widely understood among the Chinese as a male activity. In Canada, the preference for cheap male labor meant that Chinese women had less chance than their male counterparts to find employment from overseas (Chu, 2006, p. 393). Early Chinese women immigrants in British Columbia were mainly wives of Chinese merchants, and single women who were employed as sewers and domestic workers. The presence of these Chinese immigrant women workers contributed to the existing Chinese cheap labor force in the province (Chu, 2006, p. 399). The number of Chinese women arriving in Canada in the late nineteenth and early twentieth centuries was small, and those who did come were often labeled as prostitutes. The immigration of Chinese women was initially welcomed by European settlers in Canada, because these women were seen as ideal sexual partners for Chinese men (Chan, 2006, p. 394). The low ratio of Chinese women to men was perceived by white labor leaders as a sign that few Chinese immigrants would chose to settle in Canada (Chu, 2006, p. 396). This acceptance was soon replaced by fear of Chinese women because of their potential to increase the numbers of Chinese in the province, and this fear was used to justify restrictions on Chinese women immigrants into Canada. In contrast, women from Britain and other European countries and the United States were encouraged by the Canadian government to immigrate to Canada as potential wives and mothers of future nation builders and citizens (Chu, 2006, p. 395).

After WWII, economic development within Canada led to a labor shortage, and the Canadian federal government made a series of changes to immigration and citizenship policies aimed at attracting skilled labor (Hou \& Beiser, 2006, p. 137). During the 1980s, Canada introduced the Multiculturalism Act, which portrayed the image of Canada as a mosaic society (Kymlicka, 2003, p. 377), in contrast to the United States' melting-pot immigration policy. Multiculturalism has been contested and remains controversial in Canada. 
Economic changes in China, in conjunction with the changes made by the Chinese government concerning foreign travel, produced a new wave of Chinese immigrants, and since the 1980s the majority of immigrants in British Columbia have been from China (Beaujot, 1999, p. 100). Those who have left China since the 1990s are recognized by the Chinese government as the "new migrants" (Chan, 2006, p. 2). The new wave of immigrants from China to British Columbia occurred simultaneously with large numbers of Chinese immigrants from Hong Kong, Taiwan, South East Asia, America, and Australia.

While the new wave of Chinese immigrants from mainland China can be seen as an historical extension of Canada's past, it is important to recognize differences between the newcomers and the previous Chinese immigrants. Whereas earlier waves of Chinese immigrants in British Columbia were composed mainly of semiliterate male peasants from China (Chan, 2006, p. 2), recent Chinese immigrants possess more capital and skills and come from various parts of the world (Lee, 2005, p. 238). In the late 1990s and early 2000s, international surveys voted British Columbia's largest city, Vancouver, one of the most desirable places to live in the world. These surveys enhanced the multicultural image of the city and attracted a new influx of Chinese immigrants (Wickberg, 2006, p. 189).

\section{Cultural Consumption and Community Building}

It is a commonly held view among Chinese immigrants in Canada and other parts of the world that the maintenance of a collective Chinese identity outside of China is necessary and that it depends largely upon three institutions: social and business networks, Chinese-language education systems, and Chinese-language media. These institutions often exist alongside one another in communities where Chinese immigrants live (Wanning, 2005, p. 68). Historically, Chinese immigrants in Vancouver often joined voluntary associations soon after settling in the new community (Chan, 2006, p. 3 ). These associations not only play significant roles in providing assistance and a sense of belonging to new Chinese immigrants to the city (Nye, 2006, pp. 606-607), but they also provide those who are uprooted from their former homes and communities with the opportunity to redefine their identity and relations with others from similar ethnic and cultural backgrounds (Chan, 2006, p. 2). Such associations continue to play significant roles in the settlement process of Chinese immigrants in Vancouver (Wickberg, 2007, pp. 178-179). However, the emergence of online Chinese associations has altered social relations among Chinese immigrants and posed challenges to dominant meanings and representations of Chinese identity and community.

Online associations serve to connect Chinese immigrants in Vancouver to others across Canada and around the world. In addition to being used by some Chinese immigrants to promote group belonging and solidarity based on a common history, the internet is also used to challenge dominant narratives of the global Chinese identity and simultaneously construct ideas and representations of that identity (Chan, 2006, p. 18). The social relationships constructed by Chinese immigrants online further contribute to the formation of a global community of Chinese immigrants (Nye, 2006, p. 599). The internet is increasingly becoming a valuable learning tool for Chinese immigrants who are interested in learning, preserving, and transferring their cultural heritage to the next generation (Wickberg, 2007, p. 179). It is necessary to emphasize that Chinese online communities are closely connected to offline communities that also play important roles in shaping perceptions about Chinese identity among Chinese immigrant groups in Vancouver.

Before the advent of the internet, genealogical research was a leisure activity practiced by few Chinese people. However, the availability of online genealogies has encouraged many Chinese newcomers to learn about their families' histories and heritage (Chan, 2006, p. 6). Individuals can now pick and choose parts of their heritage and histories that they want to preserve and transmit to their children (p. 7). The internet offers individuals the possibility of redefining their and their childrens's identities in ways that represent them in a positive light to themselves, other Chinese people, and non-Chinese members of the community.

The various Chinese-language news media websites and online popular magazines - some of which originate in mainland China - have helped to shape the meanings of Chinese identity among Chinese immigrants in British Columbia (Wanning, 2005, p. 73). These media outlets offer alternative versions of Chinese identity that cater to the specific needs of individual members. Individuals are thus provided with the opportunity to redefine and negotiate their identities in relation to other Chinese immigrants with similar backgrounds. At the same time, community members have the option of not taking up the identities offered by these media sources.

\section{Conclusion}

As we have seen in this paper, Chinese immigration patterns in British Columbia and elsewhere in Canada are shaped by the gender, race, and national discourses of the dominant white communtiy. The extent to which these discourses ultimately shape the meaning of Chinese identity varies among Chinese immigrants. Early restrictive immigration and citizenship policies and practices of the Canadian federal government effectively contributed to the sexual imbalance among Chinese immigrants and reinforced Canada's racial and national rhetoric and representations. Although in recent years the Canadian federal government has made a series of attempts - including a recent official apology from the current Prime Minister, Stephen Harper-to redress the head tax imposed on early poor working-class Chinese immigrants, the legacy of the tax still affects many current residents of British Columbia. 
Since the 1960s, economic and political changes in Canada, China, and other parts of world have resulted in various waves of Chinese immigrants to Canada. The recent influx of Chinese people (mainly from Hong Kong, Taiwan, mainland China, Latin America, and Southeast Asia) to Vancouver has shaped the city's ethnolandscape and given rise to new and alternative meanings of Chinese ethnic and cultural identities. Differences in experiences, geographies, histories, class, education, and cultures among Chinese immigrants in British Columbia have shaped individual perceptions of what it means to be Chinese. These differences play significant roles in reinforcing, challenging, and redefining Chinese ethnic and cultural identities among various Chinese immigrant groups in Vancouver and elsewhere in Canada.

The internet provides possibilities for the new Chinese immigrant to redefine her or his ethnic and cultural membership as well as a sense of belonging to the larger community. At the same time, the internet allows individuals or groups to challenge dominant representations of Chinese ethnic and cultural identities and to construct alternative versions of Chinese culture and ethnic identity. Together, these representations offer individual Chinese immigrants the opportunity to redefine their self-identity and negotiate their belonging in various communities within the transnational context.

\section{References}

Beujot, R. P. (1999). Immigration and demographic structures. In S. S. Halli \& L. Driedger (Eds.), Immigrant Canada: Demographic, economic, and social challenges (pp. 93-115). Toronto, ON, Canada: University of Toronto Press.

Chan, B. (2006). Virtual communities and Chinese national identity. Journal of Chinese Overseas, 2(1), 1-32.

Chu, S. K. H. (2006). Repatriation as narrative resistance: Displacing orientalism and recoding harm for Chinese women of the exclusion era. Canadian Journal of Women and Law, 18(2), 387-437.

Goutor, D. (2007). Constructing the 'great menace': Canadian labour's opposition to Asian immigration, 1880-1914. The Canadian Historical Review, 88(4), 549-576.

Hou, F., \& Beiser, M. (2006). Learning the language of a new country: A ten-year study of English acquisition by South-East Asian refugees in Canada. International Migration, 44(1), 135-165.

Kymlicka, W. (2003). Being Canadian. Government and Opposition, 38(4), 357-389.

Lee, E. (2005). Orientalisms in the Americas: A hemispheric approach to Asian American history. JAAS, 8(3), 235-256.

Li, P. (2008). Reconciling with history: The Chinese-Canadian head tax redress. Journal of Chinese Overseas, 4(1), $127-140$.

Li, P. S. (2003). Destination Canada: Immigration debates and issues. Toronto, ON, Canada: Oxford University Press.

Nye, D. E. (2006). Technology and the production of difference. American Quarterly, 58(3), 597-618.

Wanning, S. (2005). Media and the Chinese diaspora: Community, consumption, and transnational imagination. Journal of Chinese Overseas, 1(1), 65-86.

Wickberg, E. (2007). Global Chinese migrants and performing Chineseness. Journal of Chinese Overseas, 3(2), 177-193. 